\title{
Influência da cama de frango e de espaçamentos entre plantas na produtividade agroeconômica de mandioquinha-salsa
}

\author{
Elissandra Pacito Torales ${ }^{1}$, Néstor Antonio Heredia Zárate ${ }^{2}$, Maria do Carmo Vieira ${ }^{3}$, Rosimeire Pereira Gassi ${ }^{4}$, \\ Natália Andressa Salles ${ }^{5}$, Jannaina Velasques da Costa Pinto ${ }^{6}$
}

\begin{abstract}
RESUMO
A cultura da mandioquinha-salsa constitui-se em ótima alternativa para pequenos e médios produtores, especialmente dentro dos conceitos de agricultura familiar. O objetivo deste trabalho foi conhecer a produtividade agroeconômica da mandioquinha-salsa cultivada com dois espaçamentos entre plantas $(20$ e $25 \mathrm{~cm})$ e formas de adição de massa seca de cama de frango ao solo [cobertura $\left(10 \mathrm{tha}^{-1}\right)$, incorporada $\left(10 \mathrm{t} \mathrm{ha}^{-1}\right)$, cobertura $\left(5 \mathrm{t} \mathrm{ha}^{-1}\right)+$ incorporada $\left(5 \mathrm{t} \mathrm{ha}^{-1}\right)$ e sem cama de frango $\left(0\right.$ t ha $\left.^{-1}\right)$ ], realizando duas colheitas independentes em diferentes estágios de maturação, $50 \%$ e $70 \%$ de senescência, que ocorreram respectivamente aos 224 e 249 dias após o plantio (DAP). As características avaliadas não foram influenciadas significativamente pela interação espaçamentos entre plantas e formas de adição de cama de frango, mas foram influenciadas pelas formas isoladas. As maiores massas de matérias frescas de folhas, coroas e os rebentos foram obtidos com o espaçamento de $25 \mathrm{~cm}$ entre plantas, nas duas colheitas. Aos $50 \%$ de senescência os aumentos foram de 27\% (folhas), $28 \%$ (coroas) e $37 \%$ (rebentos) e aos 249 DAP foram de $25 \%$ (folhas), $13 \%$ (coroas), $18 \%$ (rebentos) e $22 \%$ (raízes comerciais) em relação a $20 \mathrm{~cm}$ entre plantas. Aos $70 \%$ de senescência as melhores produções de raízes comerciais foram com a cama de frango incorporada e em cobertura + incorporada, que superaram em 10,27 tha ${ }^{-1}$ e 7,29 $\mathrm{tha}^{-1}$, respectivamente, sem a cama de frango. Para serem obtidas maiores produtividades de raízes comerciais, o cultivo em canteiros da mandioquinha-salsa 'Amarela de Carandaí' deve ser feito com espaçamento de 25 $\mathrm{cm}$ entre plantas e com a adição ao solo de cama de frango na forma incorporada, realizando a colheita com $70 \%$ de senescência da parte foliar aos 249 DAP.
\end{abstract}

Palavras-chave: Arracacia xanthorrhiza, densidade de plantas, resíduo orgânico, rentabilidade.

\section{ABSTRACT \\ Influence of broiler manure application methods and spacing arrangement between plants on Peruvian carrot economic yield}

Peruvian carrots is an excellent alternative for small and medium farmers, especially within the concepts of family farming. Thus the aim of this study was to evaluate the agricultural economic yield of this crop when managed under two plant spacing arrangements (20 and $25 \mathrm{~cm}$ between plants) and different application methods of dried broiler manure on the soil [surface-applied $\left(10 \mathrm{tha}^{-1}\right)$; incorporated to the soil $\left(10 \mathrm{t} \mathrm{ha}^{-1}\right)$; surface applied $\left(5 \mathrm{t} \mathrm{ha}^{-1}\right)+$ incorporated

\footnotetext{
${ }^{1}$ Engenheira-Agrônoma, Doutora. Departamento de Ciências Agrárias, Universidade Federal da Grande Dourados, 79804-970, Caixa Postal 533, Dourados, Mato Grosso do Sul, Brasil.ninapacito@ hotmail.com (Autora correspondente)

${ }^{2}$ Engenheiro-Agrônomo, Doutor. Departamento de Ciências Agrárias, Universidade Federal da Grande Dourados, 79804-970, Caixa Postal 533, Dourados, Mato Grosso do Sul, Brasil.nahz@ufgd.edu.br

${ }^{3}$ Engenheira-Agrônoma, Doutora. Departamento de Ciências Agrárias, Universidade Federal da Grande Dourados, 79804-970, Caixa Postal 533, Dourados, Mato Grosso do Sul, Brasil. mariavieira@ufgd.edu.br

${ }^{4}$ Engenheira-Agrônoma, Doutora. Departamento de Ciências Agrárias, Universidade Federal da Grande Dourados, 79804-970, Caixa Postal 533, Dourados, Mato Grosso do Sul, Brasil.rpgassi@yahoo.com.br

${ }^{5}$ Graduanda em Agronomia. Departamento de Ciências Agrárias, Universidade Federal da Grande Dourados, 79804970, Caixa Postal 533, Dourados, Mato Grosso do Sul, Brasil. natalia.asalles@gmail.com

${ }^{6}$ Engenheira-Agrônoma, Doutora. Departamento de Ciências Agrárias, Universidade Federal da Grande Dourados, 79804-970, Caixa Postal 533, Dourados, Mato Grosso do Sul, Brasil. jannawicca@yahoo.com.br
} 
$\left(5 \mathrm{t} \mathrm{ha}^{-1}\right)$ ]. Two harvests were performed in different stages of maturation, when plants presented $50 \%$ and $70 \%$ senescence, at 224 and 249 days after planting (DAP), respectively. The characteristics evaluated were not significantly influenced by the interaction between the plant spacing arrangements and the methods of broiler manure addition, although they were influenced by isolated studied factors. Greater fresh weights of leaves, crown and shoots were obtained under $25 \mathrm{~cm}$ plant spacing arrangement in both harvests: there were increases of $27 \%$ (leaves), $28 \%$ (crowns) and 37\% (shoots) for 50\% senescence; and 25\% (leaves), 13\% (crowns), 18\% (shoots) and 22\% (commercial roots) for $70 \%$ senescence, when compared to those obtained under $20 \mathrm{~cm}$. With $70 \%$ senescence, the greatest yields of commercial roots were attained when the addition of broiler manure was incorporated on the soil or surface applied + incorporated, outgrowing 10.27 ton ha $^{-1}$ and 7.29 ton ha $^{-1}$, respectively, in comparison with those produced without manure. Thereby, to achieve greatest yield of commercial roots and higher net income, the Peruvian carrot crops should follow spacing of $25 \mathrm{~cm}$ between plants, with broiler manure incorporated to the soil, as well harvests performed when plants reach $70 \%$ senescence, at 249 DAP.

\section{INTRODUÇÃO}

A mandioquinha-salsa é uma espécie bastante rústica, com baixa utilização de insumos e reduzido custo de produção, possuindo importância socioeconômica nas regiões onde seu cultivo é intenso. Atinge elevadas cotações e a oscilação de preços é relativamente pequena durante o ano, quando comparada a outras olerícolas, minimizando o risco de insucesso. Madeira e Souza (2004) citam que o mercado é amplo nas regiões onde o consumo de mandioquinha-salsa é comum, devido ao pequeno volume comercializado com a produção abaixo da demanda. É o caso das Regiões Sudeste e Sul, onde a cultura é extremamente compensatória. Todavia, a mandioquinhasalsa é desconhecida pela maioria da população nas regiões Norte e Nordeste e em parte do Centro-Oeste. Recentemente, porém, tem-se observado tendência de expansão da cultura para o Planalto Central.

As raízes de mandioquinha-salsa atingem a maturidade fisiológica entre sete a 14 meses após o plantio, e a cultura apresenta plasticidade de colheita que permite deixar as plantas no campo por quatro a cinco meses após atingir a maturidade fisiológica, dependendo do local (Santos, 1997). Dentre os tratos culturais utilizados para a implantação da cultura da mandioquinha-salsa, a população de plantas tem efeito marcante sobre a produção e altura de plantas, já que a competição por água, luz e nutrientes, em plantios densos, pode contribuir para a redução da capacidade produtiva, incidindo em maior ou menor grau na produtividade da espécie (Heredia Zárate et al., 2009) na qualidade das raízes obtidas e nos custos de produção.

Gomes et al. (2010), avaliando a produção de mudas e de raízes comerciais de mandioquinha-salsa do clone 'Amarela de Carandaí' em razão de espaçamentos entre plantas (20 e $25 \mathrm{~cm}$ ) e amontoas, com colheita em duas épocas (211 e 255 DAP), obtiveram maior produção de raízes comerciais com o cultivo no espaçamento de $25 \mathrm{~cm}$ entre plantas, duas amontoas e na colheita aos 255 dias após o plantio.

O uso de resíduos orgânicos adicionados ao solo é uma prática recomendada para a produção de mandioquinha-salsa, já que as características benéficas ao solo têm efeito pronunciado para essa espécie que, por ter sua parte comercial subterrânea, exige solos bem-estruturados e com melhores condições para o desenvolvimento das raízes de reserva (Vieira \& Casali, 1997). Essa prática favorece a manutenção da matéria orgânica do solo, melhorando suas propriedades físicas, químicas e biológicas, contribuindo para o aumento da produção (Kiehl, 2010).

Torales et al. (2010), avaliando a produtividade de mandioquinha-salsa 'Amarela de Carandaí', cultivada em

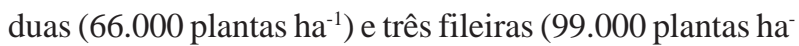
1) de plantas no canteiro, com espaçamento de 60 e 33,3 cm entre fileiras, respectivamente, e doses de $0,5,10,15 \mathrm{e}$ $20 \mathrm{t} \mathrm{ha}^{-1} \mathrm{de}$ cama de frango em cobertura do solo, em duas épocas de colheita, observaram que a maior produtividade de raízes comerciais $\left(14 \mathrm{t} \mathrm{ha}^{-1}\right)$ foi das plantas cultivadas com três fileiras e $20 \mathrm{t} \mathrm{ha}^{-1}$ de cama de frango na cobertura de solo, realizando a colheita aos 248 dias após o plantio, com $70 \%$ de senescência da parte aérea.

$\mathrm{Na}$ atividade agrícola, é essencial o estudo da rentabilidade e o acompanhamento de custos (Melo et al., 2009). Desse modo, os custos envolvidos na produção agrícola podem ser determinantes do sucesso ou do fracasso do produtor rural. Isso porque a rentabilidade consiste, em geral, na comparação da receita com o custo de produção, o que determina o lucro (Silva et al., 2001, citado por Terra et al., 2006). 
Graciano et al. (2007), avaliando a produtividade e a renda bruta da mandioquinha-salsa 'Branca', cultivada com 50 e $60 \mathrm{~cm}$ entre fileiras dentro do canteiro e espaçamentos de 15, 20 e $25 \mathrm{~cm}$ entre plantas, que resultaram nas populações de 87.912; 66.000 ; e 52.800 plantas $\mathrm{ha}^{-1}$, respectivamente, concluíram que o produtor de mandioquinha-salsa pode cultivar o clone Branca utilizando espaçamento de $20 \mathrm{~cm}$ entre plantas dentro das fileiras e de $50 \mathrm{~cm}$ ou $60 \mathrm{~cm}$ entre fileiras dentro do canteiro para obter renda bruta de $\mathrm{R} \$ 83.940 \mathrm{ha}^{-1}$ ou $\mathrm{R} \$ 83.124$ ha $^{-1}$, respectivamente.

O objetivo do presente trabalho foi investigar a produtividade agroeconômica da mandioquinha-salsa 'Amarela de Carandaí', cultivada com dois espaçamentos entre plantas e diferentes formas de adição de cama de frango ao solo, em duas épocas de colheita para a região de Dourados-MS.

\section{MATERIAL E MÉTODOS}

O experimento foi conduzido em área do Horto de Plantas Medicinais (HPM) da Faculdade de Ciências Agrárias-FCA, da Universidade Federal da Grande DouradosUFGD, em Dourados-MS, entre abril de 2009 e janeiro de 2010. A área experimental situa-se em $22^{\circ} 11^{\prime} 44^{\prime \prime} \mathrm{S}$, e $54^{\circ}$ 56' $08^{\prime \prime}$ W e altitude de $430 \mathrm{~m}$. O clima da região, segundo a classificação de Köppen, é Mesotérmico Úmido, do tipo Cwa, com temperaturas e precipitações médias anuais variando de 20 a $24^{\circ} \mathrm{C}$ e de 1.250 a $1.500 \mathrm{~mm}$, respectivamente. O solo é do tipo Latossolo Vermelho distroférrico, de textura muito argilosa (Embrapa, 1999). Foi realizada a análise dos atributos químicos do solo, na área do experimento, antes do plantio e após a colheita, em função dos tratamentos, e a análise química da cama de frango utilizada no experimento, no Laboratório de Fertilidade do Solo, FCA-UFGD.

Tabela 1. Matéria fresca de folhas, coroas e rebentos de plantas de mandioquinha-salsa 'Amarela de Carandaí' cultivadas em dois espaçamentos entre plantas e diferentes formas de adição de cama de frango ao solo e colhidas com $50 \%$ e $70 \%$ de senescência da parte foliar.

\begin{tabular}{|c|c|c|c|c|c|c|}
\hline \multirow{3}{*}{$\begin{array}{l}\text { Fatores } \\
\text { em estudo }\end{array}$} & \multicolumn{6}{|c|}{ Matéria fresca $\left(\mathrm{t} \mathrm{ha}^{-1}\right)$} \\
\hline & \multicolumn{2}{|c|}{ Folha } & \multicolumn{2}{|c|}{ Coroa } & \multicolumn{2}{|c|}{ Rebento } \\
\hline & $50 \%$ & $70 \%$ & $50 \%$ & $70 \%$ & $50 \%$ & $70 \%$ \\
\hline \multicolumn{7}{|c|}{ Espaçamentos (cm) } \\
\hline 20 & $4,29 \mathrm{~b}$ & $3,43 \mathrm{~b}$ & $3,78 \mathrm{~b}$ & $3,03 \mathrm{a}$ & $2,12 \mathrm{~b}$ & $4,63 \mathrm{~b}$ \\
\hline 25 & $5,86 \mathrm{a}$ & $4,59 \mathrm{a}$ & $5,25 \mathrm{a}$ & $3,47 \mathrm{a}$ & $3,37 \mathrm{a}$ & 5,65 a \\
\hline \multicolumn{7}{|c|}{ Forma de adição da cama de frango } \\
\hline Sem & $3,73 \mathrm{~b}$ & $2,69 \mathrm{~b}$ & $3,69 \mathrm{a}$ & $2,87 \mathrm{a}$ & $2,03 \mathrm{~b}$ & $3,59 \mathrm{c}$ \\
\hline Cobertura (C) & $4,08 \mathrm{~b}$ & $3,91 \mathrm{ab}$ & $4,55 \mathrm{a}$ & $3,24 \mathrm{a}$ & $2,34 \mathrm{ab}$ & $4,67 \mathrm{bc}$ \\
\hline Incorporado (I) & $7,31 \mathrm{a}$ & $4,84 \mathrm{a}$ & $4,90 \mathrm{a}$ & $3,29 \mathrm{a}$ & $3,70 \mathrm{a}$ & $6,43 \mathrm{a}$ \\
\hline $\mathrm{C}+\mathrm{I}$ & $5,17 \mathrm{ab}$ & $4,59 \mathrm{ab}$ & $4,91 \mathrm{a}$ & $3,58 \mathrm{a}$ & $2,90 \mathrm{ab}$ & $5,87 \mathrm{ab}$ \\
\hline $\mathrm{CV}(\%)$ & 46,21 & 39,90 & 28,39 & 24,03 & 49,24 & 25,07 \\
\hline
\end{tabular}

Médias seguidas pelas mesmas letras nas colunas, dentro de cada época de colheita, não diferem entre si pelo teste F, para espaçamentos entre plantas e pelo teste de Tukey, para formas de adição de cama-de-frango, a 5\% de probabilidade.

Tabela 2. Matéria fresca de raiz comercial e raiz não comercial de plantas de mandioquinha-salsa 'Amarela de Carandaí' cultivadas em dois espaçamentos entre plantas e diferentes formas de adição de cama-de-frango ao solo e colhidas com $50 \%$ e $70 \%$ de senescência da parte foliar.

\begin{tabular}{|c|c|c|c|c|}
\hline \multirow{3}{*}{$\begin{array}{l}\text { Fatores } \\
\text { em estudo }\end{array}$} & \multicolumn{4}{|c|}{ Matéria fresca $\left(t h^{-1}\right)$} \\
\hline & \multicolumn{2}{|c|}{ Raiz comercial } & \multicolumn{2}{|c|}{ Raiz não comercial } \\
\hline & $50 \%$ & $70 \%$ & $50 \%$ & $70 \%$ \\
\hline \multicolumn{5}{|c|}{ Espaçamentos (cm) } \\
\hline 20 & $6,44 \mathrm{~b}$ & $10,11 \mathrm{~b}$ & $2,05 \mathrm{~b}$ & $2,62 \mathrm{a}$ \\
\hline 25 & $8,93 \mathrm{a}$ & $13,00 \mathrm{a}$ & $3,02 \mathrm{a}$ & $2,88 \mathrm{a}$ \\
\hline \multicolumn{5}{|c|}{ Forma de adição da cama de frango } \\
\hline Sem & $4,55 \mathrm{~b}$ & $5,69 \quad \mathrm{c}$ & $2,48 \mathrm{a}$ & $2,71 \mathrm{a}$ \\
\hline Cobertura $(\mathrm{C})$ & $8,49 \mathrm{a}$ & $11,59 \mathrm{~b}$ & $2,35 \mathrm{a}$ & $2,74 \mathrm{a}$ \\
\hline Incorporado (I) & $9,68 \mathrm{a}$ & $15,96 \mathrm{a}$ & $2,55 \mathrm{a}$ & $2,47 \mathrm{a}$ \\
\hline $\mathrm{C}+\mathrm{I}$ & $8,01 \mathrm{a}$ & $12,98 \mathrm{ab}$ & $2,76 \mathrm{a}$ & $3,08 \mathrm{a}$ \\
\hline $\mathrm{CV}(\%)$ & 30,51 & 29,64 & 44,19 & 31,91 \\
\hline
\end{tabular}

Médias seguidas pelas mesmas letras nas colunas, dentro de cada época de colheita, não diferem entre si pelo teste $\mathrm{F}$ para espaçamentos entre plantas e pelo teste de Tukey para formas de adição de cama de frango, a 5\% de probabilidade. 


\section{Fase de campo}

Foi estudada a mandioquinha-salsa 'Amarela de Carandaí' cultivada com dois espaçamentos entre plantas na fileira (20 e $25 \mathrm{~cm}$ ) combinados com quatro diferentes formas de adição de cama de frango ao solo (base matéria seca): 1) em cobertura na taxa de $\left.10 \mathrm{t} \mathrm{ha}^{-1}, 2\right)$ incorporada na taxa de $10 \mathrm{tha}^{-1}, 3$ ) forma combinada ou mista $5 \mathrm{t} \mathrm{ha}^{-1}$ em cobertura e $5 \mathrm{t} \mathrm{ha}^{-1}$ incorporada e 4) sem cama de frango. Os oito tratamentos proviram do esquema fatorial $2 \times 4$, arranjados no delineamento experimental de blocos casualizados, com cinco repetições. A área total de cada parcela foi de 4,5 $\mathrm{m}^{2}$ (1,5 $\mathrm{m}$ de largura por 3,0 m de comprimento) e área útil de $3,0 \mathrm{~m}^{2}$ (1,0 $\mathrm{m}$ de largura por 3,0 $\mathrm{m}$ de comprimento), onde foram alocadas três fileiras de plantas com espaçamento de $0,33 \mathrm{~m}$. As populações correspondentes ao plantio com 20 e $25 \mathrm{~cm}$ entre plantas dentro da fileira foram de 99.000 e 79.200 plantas ha ${ }^{-1}$, respectivamente.

Para a implantação do experimento, o terreno foi preparado duas semanas antes do plantio, com uma aração e uma gradagem e, posteriormente, foram levantados os canteiros com rotoencanteirador. $\mathrm{Na}$ segunda passagem do implemento, foi incorporada a cama de frango nas parcelas correspondentes.
Para o plantio foram utilizados rebentos originados de plantas remanescentes de experimentos conduzidos no Horto de Plantas Medicinais da UFGD. No dia anterior ao plantio os rebentos foram selecionados e classificados visualmente em cinco grupos, de acordo com os tamanhos, com massas entre 12,26 g e $2,73 \mathrm{~g}$. Cada grupo foi sorteado para ser utilizado em uma repetição.

No dia do plantio, as mudas foram preparadas com o corte da parte aérea, deixando-se cerca de $2,0 \mathrm{~cm}$ de pecíolo, e com o corte da parte basal, transversalmente. $\mathrm{O}$ plantio foi feito manualmente, deixando descobertos os ápices dos rebentos e, imediatamente, foi realizada a distribuição da cama de frango em cobertura do solo, nas parcelas correspondentes.

As irrigações foram feitas utilizando-se o sistema de aspersão, ocorrendo na fase inicial até quando as plantas apresentaram entre 15 e $20 \mathrm{~cm}$ de altura. Os turnos de rega foram de dois dias. Posteriormente, até os 180 dias, os turnos de rega foram de três a quatro dias e nos dois meses finais uma vez por semana. O controle das plantas infestantes foi feito com enxada entre os canteiros e manualmente dentro dos canteiros. Não foram detectadas ocorrências de pragas ou doenças.

Tabela 3. Atributos químicos de amostras do solo colhidas na área experimental antes do plantio e após as colheitas da mandioquinhasalsa 'Amarela de Carandaí'

\begin{tabular}{|c|c|c|c|c|c|}
\hline \multirow{3}{*}{ Atributos do solo ${ }^{1}$} & \multirow{3}{*}{ Antes do plantio } & \multicolumn{4}{|c|}{ Após as colheitas* } \\
\hline & & \multicolumn{4}{|c|}{ Formas de adição de cama de frango } \\
\hline & & Sem & Cobertura & Incorporada & Cob.+Inc. \\
\hline $\mathrm{pH}$ em $\mathrm{CaCl}_{2}$ & 5,0 & 4,8 & 5,1 & 5,3 & 5,3 \\
\hline $\mathrm{pH}$ em água & 5,3 & 5,3 & 5,5 & 5,7 & 5,6 \\
\hline$P\left(\mathrm{mg} \mathrm{dm}^{-3}\right)$ & 40,0 & 51,0 & 85,5 & 78,0 & 91,0 \\
\hline $\mathrm{K}\left(\mathrm{mmol}_{\mathrm{c}} \mathrm{dm}^{-3}\right)$ & 2,4 & 3,5 & 4,5 & 4,0 & 4,5 \\
\hline $\mathrm{Al}^{+3}\left(\mathrm{mmol}_{\mathrm{c}} \mathrm{dm}^{-3}\right)$ & 0,6 & 0,6 & 0,6 & 0,9 & 0,9 \\
\hline $\mathrm{Ca}\left(\mathrm{mmol}_{\mathrm{c}} \mathrm{dm}^{-3}\right)$ & 36,0 & 43,0 & 43,0 & 42,0 & 44,0 \\
\hline $\operatorname{Mg}\left(\mathrm{mmol}_{\mathrm{c}} \mathrm{dm}^{-3}\right)$ & 16,0 & 19,0 & 25,5 & 21,0 & 22,0 \\
\hline $\mathrm{H}+\mathrm{Al}\left(\mathrm{mmol}_{\mathrm{c}} \mathrm{dm}^{-3}\right)$ & 53,0 & 64,0 & 56,0 & 54,0 & 56,0 \\
\hline $\mathrm{SB}\left(\mathrm{mmol}_{\mathrm{c}} \mathrm{dm}^{-3}\right)$ & 54,4 & 64,9 & 73,0 & 66,5 & 70,5 \\
\hline $\mathrm{CTC}\left(\mathrm{mmol}_{\mathrm{c}} \mathrm{dm}^{-3}\right)$ & 107,4 & 128,9 & 129,0 & 120,5 & 126,5 \\
\hline $\mathrm{V}(\%)$ & 50,0 & 51,0 & 54,5 & 53,5 & 55,0 \\
\hline \multicolumn{6}{|c|}{ Atributos da cama de frango ${ }^{1}$} \\
\hline \multicolumn{2}{|l|}{ Umidade total } & \multicolumn{4}{|c|}{20,74} \\
\hline \multicolumn{2}{|c|}{ Matéria orgânica total (\%) } & \multicolumn{4}{|c|}{52,66} \\
\hline \multicolumn{2}{|l|}{ C orgânico $\left(\mathrm{g} \mathrm{kg}^{-1}\right)$} & \multicolumn{4}{|c|}{205,6} \\
\hline \multicolumn{2}{|l|}{ Densidade $\left(\mathrm{mg} \mathrm{cm}^{-3}\right)$} & \multicolumn{4}{|c|}{0,64} \\
\hline \multicolumn{2}{|l|}{$\mathrm{pH}(\%)$} & \multicolumn{4}{|c|}{7,14} \\
\hline \multicolumn{2}{|l|}{$\mathrm{K}$ total $\left(\mathrm{g} \mathrm{kg}^{-1}\right)$} & \multicolumn{4}{|c|}{24,3} \\
\hline \multicolumn{2}{|l|}{$\mathrm{N}$ total $\left(\mathrm{g} \mathrm{kg}^{-1}\right)$} & \multicolumn{4}{|c|}{18,7} \\
\hline \multicolumn{2}{|l|}{$P$ total $\left(\mathrm{g} \mathrm{kg}^{-1}\right)$} & \multicolumn{4}{|c|}{28,5} \\
\hline \multicolumn{2}{|l|}{$\mathrm{C} / \mathrm{N}$} & \multicolumn{4}{|c|}{11,0} \\
\hline
\end{tabular}

"Média dos valores obtidos após as colheitas realizadas aos 50\% e 70\% de senescência da parte foliar.

${ }^{1}$ Análises feitas no Laboratório de Solos da FCA/UFGD. 
Foram realizas duas colheitas, em diferentes estágios de maturação, $50 \%$ e $70 \%$ de senescência da parte foliar, que ocorreram respectivamente aos 224 e 249 dias após o plantio (DAP) (Heredia Zárate et al., 2009).

Nos dias de colheita foram efetuadas avaliações de massas de matéria fresca e seca (massa obtida após a secagem do material em estufa com ventilação forçada de ar, por 72 horas, à temperatura de $65^{\circ} \mathrm{C} \pm 2{ }^{\circ} \mathrm{C}$ ) de folhas, rebentos, coroas, raízes comerciais (massas superiores a $25 \mathrm{~g}$ ) e raízes não comerciais (massas inferiores a $25 \mathrm{~g}$ e as danificadas). Também foram determinados os números de rebentos e de raízes comerciais e não comerciais.

Os dados obtidos foram submetidos à análise de variância, e quando se detectaram diferenças significativas pelo teste $\mathrm{F}$ as médias foram comparadas por Tukey, a $5 \%$ de probabilidade, usando-se o programa estatístico Sisvar versão 5.0 (Ferreira, 2007).

\section{Avaliação agroeconômica}

Para determinar a sustentabilidade do trabalho, foram realizadas estimativas dos custos de produção e das rendas bruta e líquida, considerando-se as produções de matéria fresca de raízes comercializáveis e a média do preço pago ao agricultor de Dourados-MS, por cada quilograma de raiz de mandioquinha-salsa. A renda líquida foi determinada pela renda bruta menos os custos de produção por hectare cultivado.

\section{RESULTADOS E DISCUSSÃO}

\section{Produções}

As características avaliadas não foram influenciadas significativamente pela interação entre os espaçamentos e formas de adição de cama de frango. As produções de matéria fresca de folhas e rebentos foram influenciadas

Tabela 4. Custos de produção de um hectare de mandioquinha-salsa 'Amarela de Carandaí' cultivada sem cama de frango e com dois espaçamentos entre plantas, colhidas com $50 \%$ e $70 \%$ de senescência da parte foliar

\begin{tabular}{|c|c|c|c|c|c|c|c|c|}
\hline \multirow{3}{*}{$\begin{array}{l}\text { Componentes } \\
\text { do custo }\end{array}$} & \multicolumn{4}{|c|}{$50 \%$ de senescência } & \multicolumn{4}{|c|}{ 70\% de senescência } \\
\hline & \multicolumn{2}{|l|}{20} & \multicolumn{2}{|l|}{25} & \multicolumn{2}{|l|}{20} & \multicolumn{2}{|l|}{25} \\
\hline & Quantidade & $\begin{array}{c}\text { Custo } \\
(\mathbf{R} \$)\end{array}$ & Quantidade & $\begin{array}{c}\text { Custo } \\
\text { (R\$) }\end{array}$ & Quantidade & $\begin{array}{c}\text { Custo } \\
(\mathbf{R} \$)\end{array}$ & Quantidade & $\begin{array}{c}\text { Custo } \\
(\mathbf{R} \$)\end{array}$ \\
\hline \multicolumn{9}{|l|}{ 1. Custos variáveis } \\
\hline \multicolumn{9}{|l|}{ Insumos } \\
\hline Mudas $^{1}$ & $639,54 \mathrm{~kg}$ & 1.279 & $511,63 \mathrm{~kg}$ & 1.023 & $639,54 \mathrm{~kg}$ & 1.279 & $511,63 \mathrm{~kg}$ & 1.023 \\
\hline Cama de frango $^{2}$ & - & - & - & - & - & - & - & - \\
\hline \multicolumn{9}{|l|}{ Mão de obra } \\
\hline Plantio & $8 \mathrm{H} / \mathrm{D}$ & 200 & $8 \mathrm{H} / \mathrm{D}$ & 200 & $8 \mathrm{H} / \mathrm{D}$ & 200 & $8 \mathrm{H} / \mathrm{D}$ & 200 \\
\hline Irrigação & $8 \mathrm{H} / \mathrm{D}$ & 200 & $8 \mathrm{H} / \mathrm{D}$ & 200 & $9 \mathrm{H} / \mathrm{D}$ & 225 & $9 \mathrm{H} / \mathrm{D}$ & 225 \\
\hline Capinas & $20 \mathrm{H} / \mathrm{D}$ & 500 & $20 \mathrm{H} / \mathrm{D}$ & 500 & $20 \mathrm{H} / \mathrm{D}$ & 500 & $20 \mathrm{H} / \mathrm{D}$ & 500 \\
\hline Colheita & $30 \mathrm{H} / \mathrm{D}$ & 750 & $30 \mathrm{H} / \mathrm{D}$ & 750 & $30 \mathrm{H} / \mathrm{D}$ & 750 & $30 \mathrm{H} / \mathrm{D}$ & 750 \\
\hline \multicolumn{9}{|l|}{ Maquinários } \\
\hline Bomba de irrigação & $64 \mathrm{~h}$ & 640 & $64 \mathrm{~h}$ & 640 & $71,00 \mathrm{~h}$ & 710 & $71 \mathrm{~h}$ & 710 \\
\hline Trator & $4 \mathrm{~h}$ & 240 & $4 \mathrm{~h}$ & 240 & $4,00 \mathrm{~h}$ & 240 & $4 \mathrm{~h}$ & 240 \\
\hline Subtotal $1(\mathrm{R} \$)$ & & 3.809 & & 3.553 & & 3.904 & & 3.648 \\
\hline \multicolumn{9}{|l|}{ 2. Custos fixos } \\
\hline Benfeitoria & 224 dias & 336 & 224 dias & 336 & 249 dias & 373 & 249 dias & 373 \\
\hline Remuneração da terra & 1 ha & 150 & 1 ha & 150 & 1 ha & 150 & 1 ha & 150 \\
\hline Subtotal $2(\mathrm{R} \$)$ & & 486 & & 486 & & 523 & & 523 \\
\hline \multicolumn{9}{|l|}{ 3. Outros custos } \\
\hline Imprevistos (10\% ST1) & - & 380 & - & 355 & & 390 & & 364 \\
\hline Administração (5\% ST1) & 一 & 190 & & 177 & & 195 & & 182 \\
\hline Subtotal 3 & - & 570 & - & 532 & - & 585 & - & 546 \\
\hline TOTAL & & 4.865 & & 4.571 & & 5.012 & & 4.717 \\
\hline Juro trimestral $(2,16 \%)$ & 3 & 315 & & 296 & & 324 & & 305 \\
\hline TOTAL GERAL/ha & - & 5.180 & - & 4.867 & & 5.336 & & 5.022 \\
\hline
\end{tabular}

Adaptado de Heredia Zárate et al. (1994) e Terra et al. (2006). ${ }^{1}$ Custo: Quantidade de mudas multiplicada pelo preço de $\mathrm{R} \$ 2,00 \mathrm{~kg}^{-1}$ pago ao produtor. Fonte: Santos, 2010. ${ }^{2}$ Custo da cama de frango $=\mathrm{R} \$ 80,00$ por tonelada.

Rev. Ceres, Viçosa, v. 61, n.2, p. 162-171, mar/abr, 2014 
significativamente pelo espaçamento entre plantas e pelas formas de adição de cama de frango, em forma isolada, aos $50 \%$ e $70 \%$ de senescência (224 e 249 DAP, respectivamente), e as produções de matéria fresca de coroa, pelo espaçamento entre plantas aos $50 \%$ de senescência (Tabela 1). As maiores produções de folhas, coroas e rebentos foram obtidas com o espaçamento de $25 \mathrm{~cm}$ entre plantas nas duas colheitas. Aos $50 \%$ de senescência os aumentos foram de $27 \%$ (folhas), $28 \%$ (coroas) e $37 \%$ (rebentos) e aos $70 \%$ de senescência foram de $25 \%$ (folhas), $13 \%$ (coroas) e $18 \%$ (rebentos). Esse resultado mostra que o menor espaçamento, $20 \mathrm{~cm}$ entre plantas, induziu à pressão populacional, que diminui a capacidade produtiva da planta, devido à competição por fatores de crescimento, como luz, nutrientes e água, o que resultou em decréscimo da produção (Marschner, 2005).
Quanto à adição da cama de frango ao solo, a forma incorporada foi a que induziu as maiores produções de massa de folhas e rebentos, com aumentos, respectivamente, de $3,58 \mathrm{t} \mathrm{ha}^{1}(+48 \%)$ e $1,67 \mathrm{tha}^{1}(+45 \%)$ aos 224 DAP e $2,15 \mathrm{t} \mathrm{ha}^{1}(+44 \%)$ e $2,84 \mathrm{t} \mathrm{ha}^{1}(+44 \%)$ aos $70 \%$ de senescência, em relação ao tratamento sem a adição da cama de frango, que foi aquele em que se encontraram as menores médias de produção. Esses resultados sugerem que a cama de frango na forma incorporada pode ter induzido mudanças na aeração e na capacidade de retenção de água, aumentando, assim, a atividade dos processos microbianos no solo (Kiehl, 2010), e pelo fato da mandioquinha-salsa ter um longo ciclo vegetativo, esse resíduo teve um maior tempo para se decompor, favorecendo o crescimento e o desenvolvimento das plantas.

Tabela 5. Custos de produção de um hectare de mandioquinha-salsa 'Amarela de Carandaí' cultivada com cama de frango em cobertura do solo e com dois espaçamentos entre plantas, colhidas com 50\% e 70\% de senescência da parte foliar

\begin{tabular}{|c|c|c|c|c|c|c|c|c|}
\hline \multirow{3}{*}{$\begin{array}{l}\text { Componentes } \\
\text { do custo }\end{array}$} & \multicolumn{4}{|c|}{$50 \%$ de senescência } & \multicolumn{4}{|c|}{$70 \%$ de senescência } \\
\hline & \multicolumn{2}{|l|}{20} & \multicolumn{2}{|l|}{25} & \multicolumn{2}{|l|}{20} & \multicolumn{2}{|l|}{25} \\
\hline & Quantidade & $\begin{array}{c}\text { Custo } \\
(\mathbf{R} \$)\end{array}$ & Quantidade & $\begin{array}{c}\text { Custo } \\
(\mathbf{R} \$)\end{array}$ & Quantidade & $\begin{array}{c}\text { Custo } \\
\text { (R\$) }\end{array}$ & Quantidade & $\begin{array}{c}\text { Custo } \\
(\mathbf{R} \$)\end{array}$ \\
\hline \multicolumn{9}{|l|}{ 1. Custos variáveis } \\
\hline \multicolumn{9}{|l|}{ Insumos } \\
\hline Mudas $^{1}$ & $639,54 \mathrm{~kg}$ & 1.279 & $511,63 \mathrm{~kg}$ & 1.023 & $639,54 \mathrm{~kg}$ & 1.279 & $511,63 \mathrm{~kg}$ & 1.023 \\
\hline Cama de frango & $10 \mathrm{t}$ & 800 & $10 \mathrm{t}$ & 800 & $10 \mathrm{t}$ & 800 & $10 \mathrm{t}$ & 800 \\
\hline \multicolumn{9}{|l|}{ Mão de obra } \\
\hline Plantio & $8 \mathrm{H} / \mathrm{D}$ & 200 & $8 \mathrm{H} / \mathrm{D}$ & 200 & $8 \mathrm{H} / \mathrm{D}$ & 200 & $8 \mathrm{H} / \mathrm{D}$ & 200 \\
\hline Espalhar CF & $4 \mathrm{H} / \mathrm{D}$ & 100 & $4 \mathrm{H} / \mathrm{D}$ & 100 & $4 \mathrm{H} / \mathrm{D}$ & 100 & $4 \mathrm{H} / \mathrm{D}$ & 100 \\
\hline Irrigação & $8 \mathrm{H} / \mathrm{D}$ & 200 & $8 \mathrm{H} / \mathrm{D}$ & 200 & $9 \mathrm{H} / \mathrm{D}$ & 225 & $9 \mathrm{H} / \mathrm{D}$ & 225 \\
\hline Capinas & $20 \mathrm{H} / \mathrm{D}$ & 500 & $20 \mathrm{H} / \mathrm{D}$ & 500 & $20 \mathrm{H} / \mathrm{D}$ & 500 & $20 \mathrm{H} / \mathrm{D}$ & 500 \\
\hline Colheita & $30 \mathrm{H} / \mathrm{D}$ & 750 & $30 \mathrm{H} / \mathrm{D}$ & 750 & $30 \mathrm{H} / \mathrm{D}$ & 750 & $30 \mathrm{H} / \mathrm{D}$ & 750 \\
\hline \multicolumn{9}{|l|}{ Maquinários } \\
\hline Bomba de irrigação & $64 \mathrm{~h}$ & 640 & $64 \mathrm{~h}$ & 640 & $71 \mathrm{~h}$ & 710 & $71 \mathrm{~h}$ & 710 \\
\hline Trator & $4 \mathrm{~h}$ & 240 & $4 \mathrm{~h}$ & 240 & $4 \mathrm{~h}$ & 240 & $4 \mathrm{~h}$ & 240 \\
\hline Subtotal $1(\mathrm{R} \$)$ & & 4.709 & & 4.453 & & 4.804 & & 4.548 \\
\hline \multicolumn{9}{|l|}{ 2. Custos fixos } \\
\hline Benfeitoria & 224 dias & 336 & 224 dias & 336 & 249 dias & 373 & 249 dias & 373 \\
\hline Remuneração da terra & 1 ha & 150 & 1 ha & 150 & 1 ha & 150 & 1 ha & 150 \\
\hline Subtotal $2(\mathrm{R} \$)$ & & 486 & & 486 & & 523 & & 523 \\
\hline \multicolumn{9}{|l|}{ 3. Outros custos } \\
\hline Imprevistos (10\% ST1) & - & 470 & - & 445 & - & 480 & - & 454 \\
\hline Administração (5\% ST1) & 一 & 235 & & 222 & & 240 & & 227 \\
\hline Subtotal 3 & 一 & 705 & 一 & 667 & 一 & 720 & 一 & 682 \\
\hline TOTAL & & 5.900 & & 5.606 & & 6.047 & & 5.753 \\
\hline Juro trimestral $(2,16 \%)$ & 3 & 382 & & 363 & & 391 & & 372 \\
\hline TOTALGERAL/ha & - & 6.282 & - & 5.969 & & 6.438 & & 6.125 \\
\hline
\end{tabular}

Adaptado de Heredia Zárate et al. (1994) e Terra et al. (2006). ${ }^{1}$ Custo: Quantidade de mudas multiplicada pelo preço de $\mathrm{R} \$ 2,00 \mathrm{~kg}^{-1}$ pago ao produtor. Fonte: Santos, 2010. ${ }^{2}$ Custo da cama-de-frango $=\mathrm{R} \$ 80,00$ por tonelada. 
As produções de matéria fresca de raízes comerciais e não comerciais foram influenciadas significativamente pelos espaçamentos entre plantas nas duas épocas de colheita, exceto para raízes não comerciais aos $70 \%$ de senescência (Tabela 2). Quando se utilizou o espaçamento de $25 \mathrm{~cm}$, obteve-se a maior produção de matéria fresca de raízes comerciais, com aumentos de $22 \%$ em relação aos $20 \mathrm{~cm}$ entre plantas aos 70\% de senescência. Já aos 50\% de senescência essas produções foram menores, mas com aumentos de $27 \%$ com o maior espaçamento.

Os resultados deste trabalho são coerentes com os de Graciano et al. (2006), que estudando a produção de dois clones de mandioquinha-salsa (Amarela de Carandaí e Branca), observaram que as plantas mais exuberantes e que possuíam maior altura produziram maior quantidade de raízes comerciais. Isso se deve ao fato de que, ao contrário do que ocorre com os sistemas radiculares em geral, que são pouco favorecidos em termos de distribuição de nutrientes pelas plantas, as raízes reservas de mandioquinha-salsa, uma vez presentes, funcionam como drenos preferenciais. Por outro lado, são contrários aos dados de Graciano et al. (2007), os quais observaram que as plantas que apresentavam crescimento exuberante não produziam muito bem, uma vez que podem ter perdido fotoassimilados com o processo de senescência das folhas mais velhas e, com isso, deve ter existido perdas na translocação dos fotoassimilados de reserva para as raízes. Essa diferença nessas características avaliadas pode ter relação com a capacidade de autorregulação das plantas, com base no equilíbrio das relações de interferência (Larcher, 2006), por utilizarem populações diferentes de plantas.

Tabela 6. Custos de produção de um hectare de mandioquinha-salsa 'Amarela de Carandaí' cultivada com cama de frango incorporada ao solo e com dois espaçamentos entre plantas, colhida com $50 \%$ e $70 \%$ de senescência da parte foliar

\begin{tabular}{|c|c|c|c|c|c|c|c|c|}
\hline \multirow{3}{*}{$\begin{array}{l}\text { Componentes } \\
\text { do custo }\end{array}$} & \multicolumn{4}{|c|}{$50 \%$ de senescência } & \multicolumn{4}{|c|}{ 70\% de senescência } \\
\hline & \multicolumn{2}{|l|}{20} & \multicolumn{2}{|l|}{25} & \multicolumn{2}{|l|}{20} & \multicolumn{2}{|l|}{25} \\
\hline & Quantidade & $\begin{array}{c}\text { Custo } \\
(\mathbf{R} \$)\end{array}$ & Quantidade & $\begin{array}{c}\text { Custo } \\
(\mathbf{R} \$)\end{array}$ & Quantidade & $\begin{array}{c}\text { Custo } \\
(\mathbf{R} \$)\end{array}$ & Quantidade & $\begin{array}{c}\text { Custo } \\
(\mathbf{R} \$)\end{array}$ \\
\hline \multicolumn{9}{|l|}{ 1. Custos variáveis } \\
\hline \multicolumn{9}{|l|}{ Insumos } \\
\hline Mudas $^{1}$ & $639,54 \mathrm{~kg}$ & 1.279 & $511 \mathrm{~kg}$ & 1.023 & $639,54 \mathrm{~kg}$ & 1.279 & $511,63 \mathrm{~kg}$ & 1.023 \\
\hline Cama de frango & $10 \mathrm{t}$ & 800 & $10 \mathrm{t}$ & 800 & $10 \mathrm{t}$ & 800 & $10 \mathrm{t}$ & 800 \\
\hline \multicolumn{9}{|l|}{ Mão de obra } \\
\hline Plantio & $8 \mathrm{H} / \mathrm{D}$ & 200 & $8 \mathrm{H} / \mathrm{D}$ & 200 & $8 \mathrm{H} / \mathrm{D}$ & 200 & $8 \mathrm{H} / \mathrm{D}$ & 200 \\
\hline Espalhar CF & $4 \mathrm{H} / \mathrm{D}$ & 100 & $4 \mathrm{H} / \mathrm{D}$ & 100 & $4 \mathrm{H} / \mathrm{D}$ & 100 & $4 \mathrm{H} / \mathrm{D}$ & 100 \\
\hline Irrigação & $8 \mathrm{H} / \mathrm{D}$ & 200 & $8 \mathrm{H} / \mathrm{D}$ & 200 & $9 \mathrm{H} / \mathrm{D}$ & 225 & $9 \mathrm{H} / \mathrm{D}$ & 225 \\
\hline Capinas & $20 \mathrm{H} / \mathrm{D}$ & 500 & $20 \mathrm{H} / \mathrm{D}$ & 500 & $20 \mathrm{H} / \mathrm{D}$ & 500 & $20 \mathrm{H} / \mathrm{D}$ & 500 \\
\hline Colheita & $30 \mathrm{H} / \mathrm{D}$ & 750 & $30 \mathrm{H} / \mathrm{D}$ & 750 & $30 \mathrm{H} / \mathrm{D}$ & 750 & $30 \mathrm{H} / \mathrm{D}$ & 750 \\
\hline \multicolumn{9}{|l|}{ Maquinários } \\
\hline Bomba de irrigação & $64 \mathrm{~h}$ & 640 & $64 \mathrm{~h}$ & 640 & $71 \mathrm{~h}$ & 710 & $71 \mathrm{~h}$ & 710 \\
\hline Trator & $8 \mathrm{~h}$ & 480 & $8 \mathrm{~h}$ & 480 & $8 \mathrm{~h}$ & 480 & $8 \mathrm{~h}$ & 480 \\
\hline Subtotal $1(\mathrm{R} \$)$ & & 4.949 & & 4.693 & & 5.044 & & 4.788 \\
\hline \multicolumn{9}{|l|}{ 2. Custos fixos } \\
\hline Benfeitoria & 224 dias & 336 & 224 dias & 336 & 249 dias & 373 & 249 dias & 373 \\
\hline Remuneração da terra & 1 ha & 150 & 1 ha & 150 & 1 ha & 150 & 1 ha & 150 \\
\hline Subtotal $2(\mathrm{R} \$)$ & & 486 & & 486 & & 523 & & 523 \\
\hline \multicolumn{9}{|l|}{ 3. Outros custos } \\
\hline Imprevistos (10\% ST1) & - & 494 & - & 469 & & 504 & & 478 \\
\hline Administração (5\% ST1) & 一 & 247 & & 234 & & 252 & & 239 \\
\hline Subtotal 3 & - & 723 & - & 703 & - & 756 & - & 718 \\
\hline TOTAL & & 6.158 & & 5.882 & & 6.323 & & 6.029 \\
\hline Juro trimestral $(2,16 \%)$ & 3 & 399 & & 381 & & 409 & & 390 \\
\hline TOTAL GERAL/ha & - & 6.557 & - & 6.263 & & 6.732 & & 6.419 \\
\hline
\end{tabular}

Adaptado de Heredia Zárate et al. (1994) e Terra et al. (2006). ${ }^{1}$ Custo: Quantidade de mudas multiplicada pelo preço de $\mathrm{R} \$ 2,00 \mathrm{~kg}^{-1}$ pago ao produtor. Fonte: Santos, 2010. ${ }^{2}$ Custo da cama de frango $=\mathrm{R} \$ 80,00$ por tonelada. 
As produções de matéria fresca de raízes comerciais obtiveram aumentos significativos com a adição de cama de frango ao solo, nas duas colheitas (Tabela 2), comparando com o tratamento sem o uso da cama de frango. Aos $50 \%$ de senescência, as maiores produções foram obtidas quando se utilizou a cama de frango tanto na cobertura quanto nas formas incorporada e cobertura + incorporada, que superaram em 3,94 t ha-1; $5,13 \mathrm{tha}^{-1}$ e 3,46 tha-1 de matéria fresca, respectivamente, o tratamento sem a cama de frango. Aos $70 \%$ de senescência as maiores produções foram obtidas com o uso da cama de frango incorporada e em cobertura + incorporada, que superaram em 10,27 $\mathrm{tha}^{-1}$ e 7,29 $\mathrm{t} \mathrm{ha}^{-1}$, respectivamente, em relação ao tratamento sem a cama de frango, o qual foi o que apresentou as menores produções. O efeito benéfico da cama de frango pode es- tar relacionado com os aumentos dos teores de $\mathrm{P}, \mathrm{K}$ e Mg no solo (Tabela 3), que foram determinados na análise realizada em amostras obtidas no final do ciclo de cultivo. Segundo Raij (2011), os fertilizantes orgânicos são caracterizados pelos teores de matéria orgânica, teores totais de nutrientes, especialmente $\mathrm{N}, \mathrm{P}$ e K , teor de água e relação $\mathrm{C}: \mathrm{N}$.

Esses resultados são coerentes com os relatos feitos por Moreti et al. (2007), que observaram elevação do $\mathrm{P}$ extraível do solo após aplicação de cama de frango e esterco de galinha. Os resultados obtidos em relação ao aumento dos teores de K com a adição da cama de frango confirmam os encontrados por Andreola et al. (2000), Moreti et al. (2007) e Carvalho et al. (2011), que, trabalhando com adição de resíduo orgânico ao solo, detectaram aumento no teor de $\mathrm{K}$ no solo. $\mathrm{O}$ aumento na pro-

Tabela 7. Custos de produção de um hectare de mandioquinha-salsa 'Amarela de Carandaí' cultivada com cama de frango em cobertura + incorporada ao solo e com dois espaçamentos entre plantas, colhidas com $50 \%$ e $70 \%$ de senescência da parte foliar

\begin{tabular}{|c|c|c|c|c|c|c|c|c|}
\hline \multirow{3}{*}{$\begin{array}{l}\text { Componentes } \\
\text { do custo }\end{array}$} & \multicolumn{4}{|c|}{$50 \%$ de senescência } & \multicolumn{4}{|c|}{$70 \%$ de senescência } \\
\hline & \multicolumn{2}{|l|}{20} & \multicolumn{2}{|l|}{25} & \multicolumn{2}{|l|}{20} & \multicolumn{2}{|l|}{25} \\
\hline & Quantidade & $\begin{array}{c}\text { Custo } \\
(\mathbf{R} \$)\end{array}$ & Quantidade & $\begin{array}{c}\text { Custo } \\
(\mathbf{R} \$)\end{array}$ & Quantidade & $\begin{array}{c}\text { Custo } \\
(\mathbf{R} \$)\end{array}$ & Quantidade & $\begin{array}{c}\text { Custo } \\
(\mathbf{R} \$)\end{array}$ \\
\hline \multicolumn{9}{|l|}{ 1. Custos Variáveis } \\
\hline \multicolumn{9}{|l|}{ Insumos } \\
\hline Mudas $^{1}$ & $639,54 \mathrm{~kg}$ & 1.279 & $511,63 \mathrm{~kg}$ & 1.023 & $639,54 \mathrm{~kg}$ & 1.279 & $511,63 \mathrm{~kg}$ & 1.023 \\
\hline Cama de frango & $10 \mathrm{t}$ & 800 & $10 \mathrm{t}$ & 800 & $10 \mathrm{t}$ & 800 & $10 \mathrm{t}$ & 800 \\
\hline \multicolumn{9}{|l|}{ Mão de obra } \\
\hline Plantio & $8 \mathrm{H} / \mathrm{D}$ & 200 & $8 \mathrm{H} / \mathrm{D}$ & 200 & $8 \mathrm{H} / \mathrm{D}$ & 200 & $8 \mathrm{H} / \mathrm{D}$ & 200 \\
\hline Espalhar CF & $4 \mathrm{H} / \mathrm{D}$ & 100 & $4 \mathrm{H} / \mathrm{D}$ & 100 & $4 \mathrm{H} / \mathrm{D}$ & 100 & $4 \mathrm{H} / \mathrm{D}$ & 100 \\
\hline Irrigação & $8 \mathrm{H} / \mathrm{D}$ & 200 & $8 \mathrm{H} / \mathrm{D}$ & 200 & $9 \mathrm{H} / \mathrm{D}$ & 225 & $9 \mathrm{H} / \mathrm{D}$ & 225 \\
\hline Capinas & $20 \mathrm{H} / \mathrm{D}$ & 500 & $20 \mathrm{H} / \mathrm{D}$ & 500 & $20 \mathrm{H} / \mathrm{D}$ & 500 & $20 \mathrm{H} / \mathrm{D}$ & 500 \\
\hline Colheita & $30 \mathrm{H} / \mathrm{D}$ & 750 & $30 \mathrm{H} / \mathrm{D}$ & 750 & $30 \mathrm{H} / \mathrm{D}$ & 750 & $30 \mathrm{H} / \mathrm{D}$ & 750 \\
\hline \multicolumn{9}{|l|}{ Maquinários } \\
\hline Bomba de irrigação & $64 \mathrm{~h}$ & 640 & $64 \mathrm{~h}$ & 640 & $71 \mathrm{~h}$ & 710 & $71,00 \mathrm{~h}$ & 710 \\
\hline Trator & $8 \mathrm{~h}$ & 480 & $8 \mathrm{~h}$ & 480 & $8 \mathrm{~h}$ & 480 & $8,00 \mathrm{~h}$ & 480 \\
\hline Subtotal $1(\mathrm{R} \$)$ & & 5.049 & & 4.793 & & 5.144 & & 4.888 \\
\hline \multicolumn{9}{|l|}{ 2. Custos fixos } \\
\hline Benfeitoria & 224 dias & 336 & 224 dias & 336 & 249 dias & 373 & 249 dias & 373 \\
\hline$\underline{\text { Remuneração da terra }}$ & 1 ha & 150 & 1 ha & 150 & 1 ha & 150 & 1,00 & 150 \\
\hline Subtotal $2(\mathrm{R} \$)$ & & 486 & & 486 & & 523 & & 523 \\
\hline \multicolumn{9}{|l|}{ 3. Outros custos } \\
\hline Imprevistos (10\% ST1) & - & 504 & - & 479 & & 514 & & 488 \\
\hline Administração (5\% ST1) & 一 & 252 & & 239 & & 257 & & 244 \\
\hline Subtotal 3 & 一 & 757 & 一 & 718 & 一 & 771 & 一 & 732 \\
\hline TOTAL & & 6.292 & & 5.997 & & 6.439 & & 6.143 \\
\hline Juro trimestral $(2,16 \%)$ & 3 & 407 & & 388 & & 417 & & 398 \\
\hline TOTAL GERAL/ha & 一 & 6.699 & - & 6.385 & & 6.856 & & 6.541 \\
\hline
\end{tabular}

Adaptado de Heredia Zárate et al. (1994) e Terra et al. (2006). ${ }^{1}$ Custo: Quantidade de mudas multiplicada pelo preço de $\mathrm{R} \$ 2,00 \mathrm{~kg}^{-1}$ pago ao produtor. Fonte: Santos, 2010. ${ }^{2}$ Custo da cama de frango $=\mathrm{R} \$ 80,00$ por tonelada. 
Tabela 8. Produtividade, renda bruta, custo de rebentos e da cama-de-frango e renda líquida de raízes comerciais de mandioquinhasalsa 'Amarela de carandaí', cultivada sob 20 e $25 \mathrm{~cm}$ entre plantas e com diferentes formas de adição de cama-de-frango e colhidas com $50 \%$ e $70 \%$ de senescência da parte foliar

\begin{tabular}{|c|c|c|c|c|c|}
\hline \multicolumn{2}{|l|}{ Fatores em estudo } & \multirow{2}{*}{$\begin{array}{l}\text { Produtividade } \\
\qquad\left(\mathrm{Kg} \mathrm{ha}^{-1}\right)\end{array}$} & \multirow{2}{*}{$\begin{array}{c}\text { Renda bruta }{ }^{1} \\
(\mathrm{R} \$)\end{array}$} & \multirow{2}{*}{$\begin{array}{c}\text { Custo }^{2} \\
(\mathbf{R} \$)\end{array}$} & \multirow{2}{*}{$\begin{array}{c}\text { Renda Líquida } \\
\text { (R\$) }\end{array}$} \\
\hline $\begin{array}{l}\text { Espaçamentos } \\
(\mathrm{cm})\end{array}$ & $\begin{array}{c}\text { Forma de adição } \\
\text { da cama-de-frango }\end{array}$ & & & & \\
\hline \multicolumn{6}{|c|}{$50 \%$ de senescência da parte foliar } \\
\hline \multirow{4}{*}{20} & Sem & 4.520 & 11.300 & 5.180 & 6.120 \\
\hline & Cobertura $(\mathrm{C})$ & 6.480 & 16.200 & 6.282 & 9.918 \\
\hline & Incorporado (I) & 8.240 & 20.600 & 6.557 & 14.043 \\
\hline & $\mathrm{C} \times \mathrm{I}$ & 6.520 & 16.300 & 6.699 & 9.601 \\
\hline \multirow{4}{*}{25} & Sem & 4.590 & 11.475 & 4.867 & 6.608 \\
\hline & Cobertura (C) & 10.510 & 26.275 & 5.969 & 20.306 \\
\hline & Incorporado (I) & 11.120 & 27.800 & 6.263 & 21.537 \\
\hline & $\mathrm{C} \times \mathrm{I}$ & 9.510 & 23.775 & 6.385 & 17.390 \\
\hline \multicolumn{6}{|c|}{$70 \%$ de senescência da parte foliar } \\
\hline \multirow{4}{*}{20} & Sem & 4.620 & 11.550 & 5.336 & 6.214 \\
\hline & Cobertura $(\mathrm{C})$ & 10.550 & 26.375 & 6.438 & 19.937 \\
\hline & Incorporado (I) & 15.440 & 38.600 & 6.732 & 31.868 \\
\hline & $\mathrm{CxI}$ & 9.850 & 24.625 & 6.856 & 17.769 \\
\hline \multirow{4}{*}{25} & Sem & 6.770 & 16.925 & 5.022 & 11.903 \\
\hline & Cobertura (C) & 12.640 & 31.600 & 6.125 & 25.475 \\
\hline & Incorporado (I) & 16.480 & 41.200 & 6.419 & 34.781 \\
\hline & $\mathrm{C} \times \mathrm{I}$ & 16.110 & 40.275 & 6.541 & 33.734 \\
\hline
\end{tabular}

${ }^{1} \mathrm{R} \$ 2,50 \mathrm{Kg}^{-1}$. Preço pago ao produtor de mandioquinha-salsa na feira de central em Dourados-MS, dia 25/03/2011. ${ }^{2}$ Custo de produção de um hectare de mandioquinha-salsa 'Amarela de Carandaí'.

dução de raízes comerciais foi influenciado pela adição da cama de frango que, disponibilizando nutrientes ao longo do ciclo da cultura, pode ter contribuído para que a planta expressasse o seu potencial de produção.

\section{Avaliação agroeconômica}

Para o plantio de 1,0 ha de mandioquinha-salsa (Tabelas 4, 5, 6 e 7), o custo estimado variou de $\mathrm{R} \$ 1.989,00$ entre o menor custo, que correspondeu ao tratamento sem uso de cama de frango e espaçamento de $25 \mathrm{~cm}$ entre plantas, aos $50 \%$ de senescência, e o maior custo, que foi do tratamento com cama de frango em cobertura mais incorporada e espaçamento de $20 \mathrm{~cm}$ entre plantas, aos $70 \%$ de senescência.

Do custo total de produção, os custos variáveis representaram $73 \%$, para o tratamento sem uso de cama de frango e espaçamento de $25 \mathrm{~cm}$ entre plantas, aos $50 \%$ de senescência, que teve o menor custo total, e $75 \%$ para o de maior custo, que foi do tratamento cama de frango em cobertura mais incorporada e $20 \mathrm{~cm}$ entre plantas, aos $70 \%$ de senescência.

A mão de obra foi responsável por gastos entre $34 \%$ para o tratamento sem uso de cama de frango e espaçamento de $25 \mathrm{~cm}$ entre plantas, aos $50 \%$ de senescência, e $27 \%$ no tratamento com cama de frango em cobertura mais incorporada e $20 \mathrm{~cm}$ entre plantas, aos $70 \%$ de senescência. Esses dados ressaltam a importância da cultura como atividade geradora de emprego no meio rural, por meio do uso de sua mão de obra. Em relação aos insumos e maquinários, esses representaram, respectivamente, $29 \%$ e $25 \%$ no tratamento sem uso de cama de frango e espaçamento de $25 \mathrm{~cm}$ entre plantas e entre $40 \%$ e $23 \%$ no tratamento com cama de frango em cobertura mais incorporada e $20 \mathrm{~cm}$ entre plantas.

Considerando a produção média de raízes comerciais, obtida em cada tratamento, a estimativa das rendas bruta e líquida mostrou que o cultivo da mandioquinha-salsa 'Amarela de Carandaí' utilizando no plantio o espaçamento de $25 \mathrm{~cm}$ entre plantas e a cama de frango na forma incorporada foi o melhor na produção de raízes comerciais nas duas colheitas (Tabelas 8). Quando se compararam as épocas de colheita, aquele realizado com estágio de maturação de $70 \%$ de senescência da parte foliar (249 DAP) foi o que induziu a maior renda líquida, superando em $\mathrm{R} \$ 28.661$ (aumento de $82 \%$ ) a renda obtida com 50\% de senescência (224 DAP), com espaçamento de $20 \mathrm{~cm}$ entre plantas e sem o uso da cama de frango, que foi o tratamento que obteve a menor produtividade. 


\section{CONCLUSÕES}

Para se obterem maiores produtividades de raízes comerciais o cultivo em canteiros da mandioquinha-salsa 'Amarela de Carandaí' deve ser feito com espaçamento de $25 \mathrm{~cm}$ entre plantas e com a adição ao solo de cama de frango na forma incorporada, realizando a colheita com $70 \%$ de senescência da parte foliar, aos 249 DAP.

O menor custo de produção correspondeu ao tratamento sem uso de cama de frango e espaçamento de 25 $\mathrm{cm}$ entre plantas, com $50 \%$ de senescência, porém as maiores rendas bruta e líquida foram obtidas no espaçamento de $25 \mathrm{~cm}$ entre plantas e com a adição ao solo de cama de frango na forma incorporada, com $70 \%$ de senescência da parte foliar.

\section{AGRADECIMENTOS}

Ao CNPQ, pela bolsa concedida.

\section{REFERÊNCIAS}

Andreola F, Costa LM \& Olszevsk N (2000) Influência da cobertura vegetal de inverno e da adubação orgânica e, ou, mineral sobre as propriedades físicas de uma Terra Roxa Estruturada. Revista Brasileira de Ciência do Solo, 24:857-865.

Carvalho ER, Rezende PM, Andrade MJB, Passos AMA \& Oliveira JA (2011) Fertilizante mineral e resíduo orgânico sobre características agronômicas da soja e nutrientes no solo. Revista Ciência Agronômica, 42:930-939.

Embrapa (1999) Centro Nacional de Pesquisa de Solos. Sistema brasileiro de classificação de solos. Rio de Janeiro, Embrapa Solos. 412p.

Ferreira DF (2007) SISVAR: sistema de análise de variância para dados balanceados. Versão 5.0. Lavras, DEX/UFLA. (Software estatístico)

Gomes HE, Heredia Zárate NA, Vieira MC, Gassi RP, Torales EP \& Macedo RV (2010) Produção de mudas e de raízes comerciais de mandioquinha-salsa 'Amarela de Carandaí' em função de espaçamentos e amontoa. Semina Ciências Agrárias, 31:1121-1132.

Graciano JD, Heredia Zárate NA, Vieira MC, Jardim Rosa YBC \& Sediyama MAN (2007) Espaçamentos entre fileiras e entre plantas na produção da mandioquinha-salsa 'Branca'. Ciência e Agrotecnologia, 31:1688-1695.

Graciano JD, Heredia Zárate NA, Vieira MC, Jardim Rosa YBC, Sediyama MAN \& Rodrigues ET (2006) Efeito da cobertura do solo com cama-de-frango semidecomposta sobre dois clones de mandioquinha-salsa. Acta Scientiarum Agronomy, 28:365-371.

Heredia Zárate NA, Vieira MC, Graciano JD, Figueiredo PG, Blans NB \& Curioni BM (2009) Produtividade de mandioquinha-salsa sob diferentes densidades de plantio e tamanho de mudas. Ciência e Agrotecnologia, 33:139-143.

Kiehl EJ (2010) Novo Fertilizantes Orgânicos. Piracicaba, Agronômica Ceres. 248p.

Larcher W (2006) Ecofisiologia vegetal. São Carlos: Rima-Artes e Textos. 531p.

Madeira NR \& Souza RJ (2004) Mandioquinha-salsa: alternativa para o pequeno produtor. Disponível em: <http:// www.editora.ufla.br/BolTecnico/pdf/bol_60.pdf.> Acessado em: 05 de janeiro 2012.
Marschner H (2005) Mineral nutrition of higher plants. $2^{\mathrm{a}}$ ed. Orlando, Academic Press. 889p.

Melo AS, Costa BC, Brito MEB, Aguiar Netto AOA \& Viégas PRA (2009) Custo e rentabilidade na produção de batata-doce nos perímetros irrigados de Itabaiana, Sergipe. Pesquisa Agropecuária Tropical, 39:119-123.

Moreti D, Alves MC, Filho WVV \& Carvalho MP (2007) Atributos químicos de um latossolo vermelho sob diferentes sistemas de preparo, adubações e plantas de cobertura. Revista Brasileira de Ciência do Solo, 31:167-175.

Raij BV (2011) Fertilidade do solo e manejo de nutrientes. Piracicaba, International Plant Nutrition Institute. 420p.

Terra ER, Heredia Zárate NA, Vieira MC \& Mendonça PSM (2006) Proposta de cálculo e forma de adubação, com e sem amontoa, para a produção e renda bruta do milho Superdoce 'Aruba'. Acta Scientiarum Agronomy, 28:75-82.

Santos FF (1997) Utilização de mudas juvenis e do préenraizamento no impedimento da floração em mandioquinhasalsa. Informe Agropecuário, 19:27-28, 33-34.

Torales EP, Heredia Zárate NA, Vieira MC, Resende MM, Sangalli CMS \& Gassi RP (2010) Doses de cama-de-frango e densidade de plantio na produção de mandioquinha-salsa 'Amarela de Carandaí'. Semina Ciências Agrárias, 31:1165-1176.

Vieira MC \& Casali VWD (1997) Adaptação da cultura da mandioquinha-salsa à adubação orgânica. Informe Agropecuário, 19:40-42. 